\title{
Reduction Characteristics of High Phosphorus Iron Ore in Reducing Parameters Similar to Blast Furnace Conditions
}

\author{
Heba Al-Kelesh*, M. I. Nasr \\ Central Metallurgical Research and Development Institute (CMRDI), Cairo, Egypt \\ Email: *hebaalkelesh@hotmail.com
}

How to cite this paper: Al-Kelesh, H. and Nasr, M.I. (2019) Reduction Characteristics of High Phosphorus Iron Ore in Reducing Parameters Similar to Blast Furnace Conditions. Journal of Minerals and Materials Characterization and Engineering, 7, 294-306. https://doi.org/10.4236/jmmce.2019.75021

Received: July 1, 2019

Accepted: September 15, 2019

Published: September 18, 2019

Copyright $\odot 2019$ by author(s) and Scientific Research Publishing Inc. This work is licensed under the Creative Commons Attribution International License (CC BY 4.0).

http://creativecommons.org/licenses/by/4.0/

\section{c) (i) Open Access}

\begin{abstract}
The strong global demand for iron and steel has necessitated the utilization of various low grade iron ores, which are not suitable for direct utilization in ironmaking processes. The low grade iron ores cannot be dressed effectively using the traditional mineral processing methods because of complicated mineral compositions. The main problem associated with exploiting these deposits is the dissemination of fine silicate minerals and the high level of phosphorus content due to the poor liberation of iron minerals from the gangues. The present manuscript is aimed to investigate reduction properties of iron ores rich in phosphorous in order to study the suitability of using these ores in iron blast furnace. Representative technological samples of iron ore are collected from Eastern South Aswan iron ore mine in Egypt. The principal gangue contents are $\mathrm{SiO}_{2} 7.76 \%$, and $\mathrm{P}_{2} \mathrm{O}_{5} 1.13 \%$. Iron and phosphorus exist in the form of hematite $78 \%$ and apatite respectively. The ore was fired at $1000^{\circ} \mathrm{C}$ for 3 hours. The green and fired samples were isothermally reduced at conditions which closely represent the theoretical reduction conditions in different zones of blast furnace. The influence of reduction conditions on the reduction behaviour and the morphology of the reduced samples were investigated. After reduction apatite is changed to Calcium phosphate beside fayalite and quartz. The reduction rate of fired samples is greater than that for the green ones and that was confirmed by morphological examination. At cohesive zone condition, the effect of firing on reduction characteristics cannot be distinguished.
\end{abstract}

\section{Keywords}

Reduction, Aswan Iron Ore, High Phosphorus Iron Ore, Blast Furnace 


\section{Introduction}

Ironmaking is the most important step in steel manufacture and considered the most energy consumer process in ferrous metallurgy. Generally, ironmaking processes take three forms: blast furnace process $(\mathrm{BF})$, direct reduction and direct smelting processes. Amongst all the ironmaking processes, $\mathrm{BF}$ will continue to be the principal method of ironmaking.

Recently, most of the researches on blast furnace operation are designed to improve both productivity and cost, increase the efficiency of operation as well as decreasing the energy consumption. The cost of raw materials constitutes $80 \%$ of the cost of hot metal production. The most powerful means for reducing energy consumption and increase productivity in the blast furnace is the improvements in the composition of raw material especially iron ore.

On the other hand, molten iron is being produced in blast furnaces at Egyptian iron and steel company (EISCO, Helwan, Egypt) using Egyptian iron ores deposited in Baharia (El-Gedida). But it is being depleted with time and consequently EISCO will face an iron ore shortage problem in the near future. El-Gedida reserves are about $28 \%$ of the total Egyptian iron ores reserves.

Accordingly, alternatives should be found for expanding utilization of Egyptian iron ores in iron industry.

Occurrences and distribution of the iron ore types are controlled by the lithostratigraphy and morphotectonics [1]. Aswan mine is located at the south of Egypt. It contains about nine million tons of iron ores reserves. The average silica and phosphorous contents are $14.14 \%$ and $1.31 \%$ respectively [2]-[7]. The most challenge which hinders the utilization of these deposits in ironmaking technology is the high phosphorous content. That is why the investigation of reduction characteristics and morphology of these ores are considered significant issues.

Many countries have high phosphorous iron ores distributed with some large scale deposits worldwide such as: Sweden, France, Canada, Pakistan, China, northern Sudan, Nigeria and Italy [8]. It was found that several possible ways to make high quality steel from high phosphorus apatitic iron ores, operation of blast furnaces with $100 \%$ pellets burden made from enriched, dephosphorized high phosphorus ores and how to balance the composition of a DR pellet to make it "self-fluxing" in electric arc furnace steelmaking, forming a furnace slag giving minimum refractory wear.

Baioumy et al. [9] studied High-P oolitic iron ores from Aswan, Egypt. The detailed petrographic, mineralogical, and geochemical are investigated to examine their origin in addition to the texture and origin of P-bearing minerals. The appraisals indicated that these ores were formed in open space near the sediment-water interface by accretion of $\mathrm{FeO}, \mathrm{SiO}_{2}, \mathrm{Al}_{2} \mathrm{O}_{3}$, and minor amounts of other oxides around solid particles such as quartz and parts of broken ooliths. Phosphorus in these ores occurs in higher concentrations compared to the limit of $\mathrm{P}$ in the steel. It is present as massive and structureless hydroxyapatite grains 
of undefined outlines and variable size $(5-150 \mu \mathrm{m})$ inside the ooids and/or in the ferruginous groundmass. Determination of the mode of occurrence and grain size of P-bearing mineral (hydroxyapatite) support the optimum utilization of both physical and biological separation of $\mathrm{P}$ from the Aswan iron ores and thus encourage the use of these ores as raw materials in the iron making industry.

Many studies are carried out for investigation of reduction behavior of different iron ores by carbon and different reducing gases all over the world [10]-[18]. Studies on the chemical and physical properties and the reduction behavior in coal of hematite iron ores are investigated [11].

Yongsheng Sun et al. [19] studied coal-based reduction of oolitic iron ore. An oolitic iron ore was isothermally reduced by coal at $1423 \mathrm{~K}-1573 \mathrm{~K}$, and the reduction kinetics and mechanisms were investigated using the thermogravimetry (TG) technique. It was found that the reduction temperature and C/O molar ratio had significant influence on the degree of iron oxide reduction and its reduction rate. The hematite in the ore was reduced to metallic iron in the sequence of $\mathrm{Fe}_{2} \mathrm{O}_{3} \rightarrow \mathrm{Fe}_{3} \mathrm{O}_{4} \rightarrow \mathrm{FeO} \quad\left(\mathrm{FeAl}_{2} \mathrm{O}_{4}, \mathrm{Fe}_{2} \mathrm{SiO}\right) \rightarrow \mathrm{Fe}$. The mechanisms of reduction changed with reduction time. As reduction progressed, the oolitic structure was gradually destroyed, and the metallic iron aggregated concurrently.

Reduction behavior of iron ore pellets with simulated coke oven gas and natural gas was investigated by many researchers [13] [14] [15]. The highest reduction degree was obtained for the pellets reduced with reformed coke oven gas while the lowest reduction degree was exhibited by original natural gas. On the other hand, the rate of reduction with original coke oven gas was sharply increased at temperature of about $900^{\circ} \mathrm{C}$ to become higher than that of reformed natural gas.

However, blast furnace is the main technology utilizing iron ores in the form of sinter and/or pellets. The furnace can be divided into three main zones according to the thermal distribution of the burdens namely top, reverse and cohesive zone.

Based on the above background, the present study aims at investigation of reduction behavior of green and fired high phosphorous iron ore isothermally at reduction conditions simulating different zones in the blast furnace.

\section{Experimental Work}

Representative technological samples for iron ore are collected from the Eastern South Aswan. For reduction of iron ore, the thermobalance used for monitoring weight change of samples consists of vertically tube furnace wound by kanthal wire designed for attaining a maximum temperature of $1200^{\circ} \mathrm{C}$. The temperature was automatically measured and controlled by a $\mathrm{Ni} / \mathrm{Ni}-\mathrm{Cr}$ thermocouple connected to a temperature controller with indicator (Heraus $\mathrm{GmbH}-1200^{\circ} \mathrm{C}$ ). The reaction tube, which is a sintered alumina tube of $60 \mathrm{~cm}$ long and $4.2 \mathrm{~cm}$ inner diameter, is fitted inside the furnace. 
Before starting each reduction experiment, the glass towers are regularly refilled with fresh silica gel and soda lime then carbon monoxide was passed over these towers to purify it from carbon dioxide and water vapors. Silica gel towers were used for drying the carbon dioxide, hydrogen and nitrogen gases. The flows of purified gases were measured by digital flow meters (SIERRA, Smart-Trak Series 100). The reduction processes were carried out at different temperatures simulated for different zones in blast furnace as shown in Table 1.

For each reduction experiment, the furnace was heated up to the required reduction temperature, and then the sample was weighed and placed in the basket. The sample was then gradually introduced into the furnace so as to avoid thermal shock cracking and positioned in the middle of the furnace constant hot zone. First, nitrogen at a flow rate of 1 liter/min was introduced. Then after the sample soaking for 10 minutes at the reduction temperature, the reducing gas mixtures at a total flow rate of 1 liter/min were introduced. The weight loss resulted from oxygen removal from the samples was intervally recorded with time. At the end of the experiment, the basket with the reduced sample was removed and dropped by releasing its suspension wire from the balance, into a conical flask containing acetone to prevent pyrophority of the reduced sample.

Ore was compacted into briquettes of $2 \mathrm{gm}$ weight, $10 \mathrm{~mm}$ diameter and 7 $\mathrm{mm}$ height. The prepared briquettes were isothermally reduced by different ratios of $\mathrm{H}_{2} / \mathrm{CO} / \mathrm{CO}_{2} / \mathrm{N}_{2}$ (Table 1 ) which closely represent the theoretical composition of gas mixture in different parts of blast furnace which calculated with a mathematical model of blast furnace on the basis of mass and heat balance and the chemical analysis of top gases [20] [21].

Samples were fired at $1000^{\circ} \mathrm{C}$ for 3 hours then isothermally reduced by the same reduction conditions Table 1 . Finally, the reduction extent is calculated [22] [23] [24]. As reference experiment, sample is reduced at $1100^{\circ} \mathrm{C}$ by hydrogen gas (flow rate $=1 \mathrm{l} / \mathrm{min}$.) to calculate the total oxygen content $\left(w_{o}\right)$,

$$
w_{o}=w_{i}-w_{f}
$$

Reduction extent at time $t\left(R_{t}\right)$ is calculated as:

$$
R_{t}=\left(\left(w_{i}-w_{t}\right) / w_{o}\right) \times 100
$$

where,

$W_{i}=$ weight at zero time, $w_{t}=$ weight at time $t$.

\begin{tabular}{|c|c|c|c|c|c|}
\hline \multicolumn{4}{|c|}{ Gas composition, vol\% } & \multirow{2}{*}{ Different zones in blast furnace } & \multirow{2}{*}{ Temp., ${ }^{\circ} \mathrm{C}$} \\
\hline $\mathrm{H}_{2}$ & $\mathrm{CO}$ & $\mathrm{CO}_{2}$ & $\mathrm{~N}_{2}$ & & \\
\hline 8.1 & 45 & 0 & 55 & Cohesive zone & 1100 \\
\hline 5.1 & 40 & 5 & 55 & Thermal reserve zone & 927 \\
\hline 4.1 & 35 & 10 & 55 & Top zone & 700 \\
\hline
\end{tabular}

Table 1. The theoretical composition of gas mixture in different parts of blast furnace. 
The characterization of Samples was carried out using X-ray diffraction analysis at room temperature. The diffraction patterns were obtained by means of a chart recording Philips PW (1790) X-ray diffractometer using copper (K $\alpha$ ) radiation. The instrument was properly calibrated and adjusted with respect to the $\mathrm{X}$-ray source. A high voltage of $40 \mathrm{kV}$ and anode current of $30 \mathrm{~mA}$ were chosen. The connected Geiger Muller tube detector was adjusted to the order of one degree/cm for identification purposes.

The interplanar spacing (d) was derived from the observed Braggs law:

$$
2 d \sin \theta=n \lambda \text { where }(n=1)
$$

where $\lambda=1.5405$, is the wavelength associated with $\mathrm{Cu} \mathrm{K} \alpha$ radiation used. The relative intensity $\left(I / I_{o}\right)$ was calculated for all lines in the obtained diffraction patterns. X-ray fluorescence was used to obtain full chemical analysis of ore. Reflected light microscope (RLM) and Scanning electron microscope (SEM) were used to examine the microstructure of the fired as well completely reduced samples.

The effect of reduction temperature and gas composition on the reduction behavior were investigated.

\section{Results and Discussion}

\subsection{Characterization of Ores}

The characterization of high phosphorus iron ore was carried out using X-ray diffraction analysis. It can be noticed that the iron ore sample mainly contains hematite phase with total iron percent $55.7 \%$ beside some impurities such as quartz, apatite $\left[\mathrm{Ca}_{5}\left(\mathrm{PO}_{4}\right)_{3} \mathrm{~F}\right]$ and kaolinite as shown in Figure 1.

The complete chemical analysis of the iron ore used in the present work is shown in Table 2. The analysis was carried out using XRF analyzer. The ore can

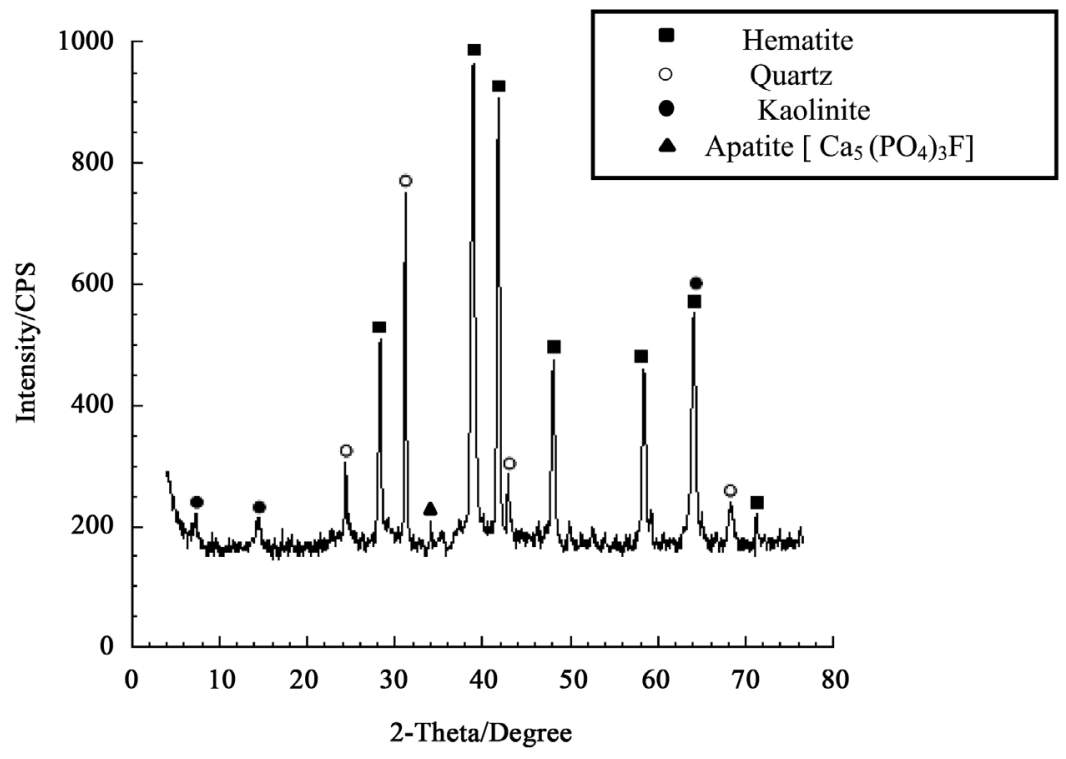

Figure 1. XRD pattern of high phosphorus ore. 
Table 2. Chemical analysis of iron ore.

\begin{tabular}{cccccccccccccc}
\hline Oxides & $\mathrm{SiO}_{2}$ & $\mathrm{Al}_{2} \mathrm{O}_{3}$ & $\mathrm{Fe}_{2} \mathrm{O}_{3}$ & $\mathrm{CaO}$ & $\mathrm{K}_{2} \mathrm{O}$ & $\mathrm{MnO}$ & $\mathrm{Na}_{2} \mathrm{O}$ & $\mathrm{MgO}$ & $\mathrm{SO}_{3}$ & $\mathrm{TiO}_{2}$ & $\mathrm{P}_{2} \mathrm{O}_{5}$ & $\mathrm{BaO}$ & $\mathrm{LOI}$ \\
\hline $\mathrm{Wt} \%$ & 7.759 & 3.479 & 78.894 & 1.93 & 0.089 & 0.2 & 0.149 & 0.856 & 0.13 & 0.268 & 1.13 & 0.09 & 4.4 \\
\hline
\end{tabular}

be considered a medium grade with total iron content $55.7 \%$. It has high content of silica and phosphorus oxide. Basicity of ore $(\mathrm{CaO}+\mathrm{MgO}) /\left(\mathrm{SiO}_{2}+\mathrm{Al}_{2} \mathrm{O}_{3}\right)$ is 0.3 .

\subsection{Reduction Characteristics of Green Ores}

The isothermal reduction curves of high phosphorus iron ore briquettes reduced under different operation conditions of reduction temperatures and gas composition simulating different zones of iron blast furnace are given in Figure 2. For each single reduction curve, the rate of reduction was highest at the early stages and decreased as reduction proceeds till the end of reduction. The rate of reduction increases by descending from top zone gas mixture with its temperature to cohesive zone gas mixture with its temperature. Such kind of phenomena can be attributed to the difference in gas composition and reduction temperatures. It's well known that increasing ratio of $\mathrm{H}_{2}$ and $\mathrm{CO}$ in the reducing gas mixture together with increasing reduction temperatures will enhance greatly the reduction reactions. Reduction of green samples by top zone and thermal reserve zone gas mixtures was not completed and stopped at about $35 \%$ and $70 \%$ reduction extent respectively.

The microstructure of reduced samples were examined by reflected light microscope as shown in Figure 3(a) and Figure 3(b). It was observed that the sample reduced by top zone reduction conditions have large macro-pores and few amount of micro-pores. On the other hand, the sample reduced by thermal reserve zone reduction condition has many macro and micro pores distributed homogenously in its structure with greater amount of iron grains Figure 3(b).

The whole effect of reduction conditions on the microstructures changes accompanying reduction processes can be observed in Figure 4. The microstructure of samples reduced by thermal reserve zone conditions compared with unreduced green samples show that hematite is well developed euhedral crystals with the same size but apatite is massive and structureless grains of variable size. Hematite grains are accumulated with each other with some micro- and macro-pores between them. After reduction, the grains shape were changed to semi-sphere, semi-melted and connected to each other.

\subsection{Investigation of the Firing Effect on Reduction Behavior of High Phosphorous Iron Ore}

X-ray diffraction analysis was carried out for fired samples. It can be noticed that fired samples mainly contains hematite phase with crystalline size (41.5 - 82.6) $\mathrm{nm}$ beside some Quartz, fayalite and calcium phosphate as shown in Figure $5(a)$. 


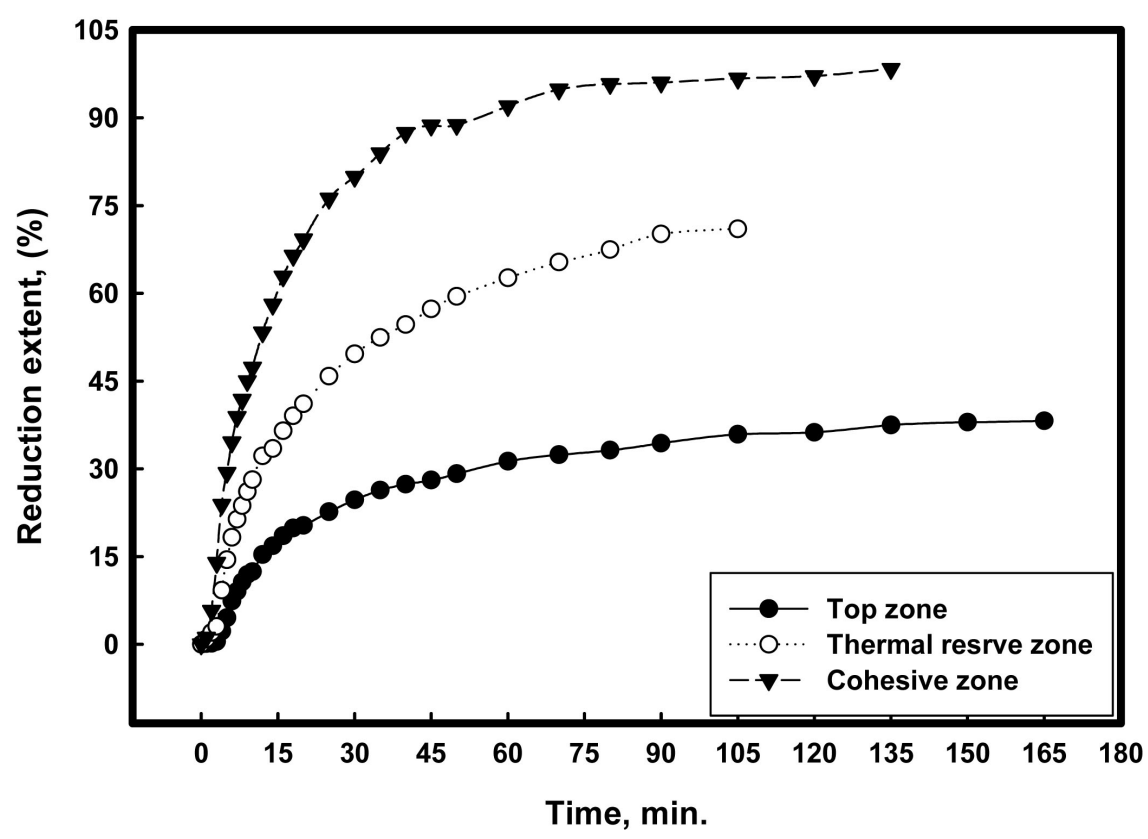

Figure 2. Reduction behavior of green samples in different zones of blast furnace.
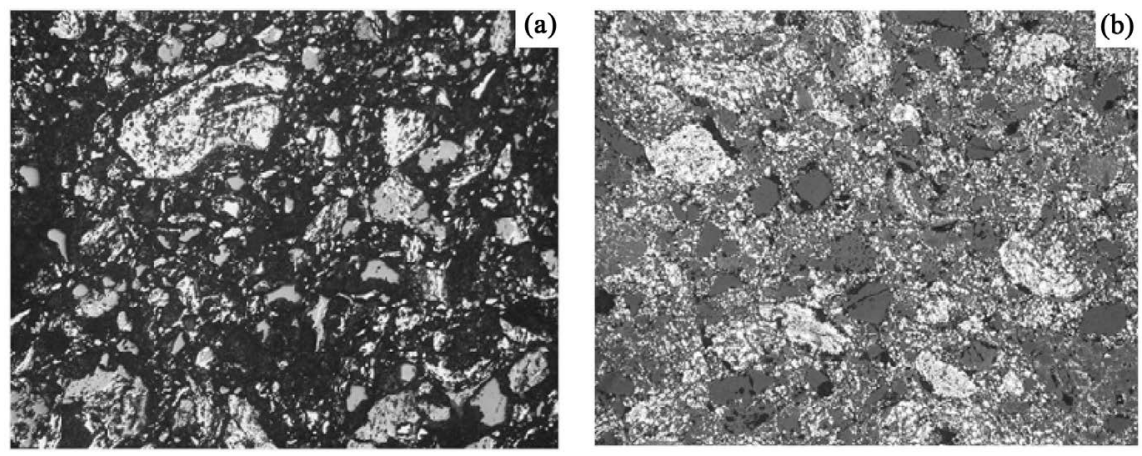

Figure 3. Optical microscope images for samples reduced by different reduction conditions. (a) Top zone; (b) Thermal reserve zone $(x=100)$.
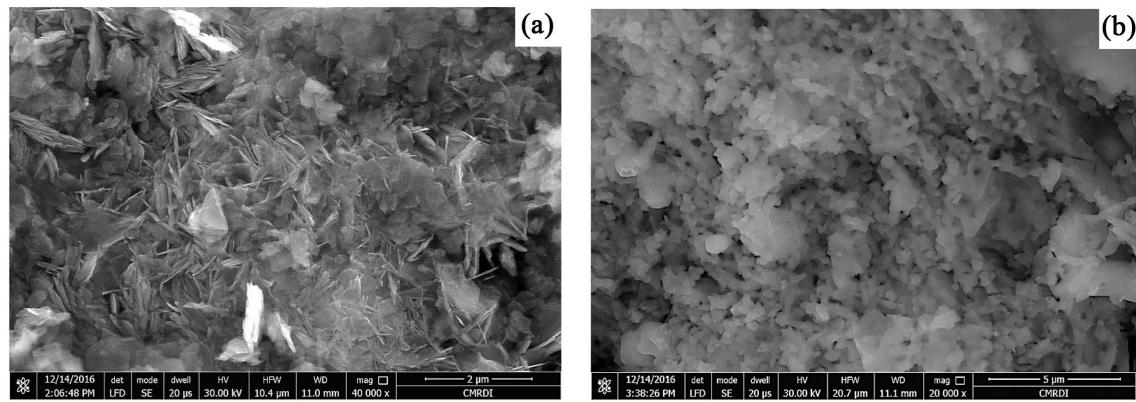

Figure 4. FESEM images for. (a) Green sample; (b) Reduced sample at thermal reserve zone conditions.

\subsection{Reduction Characteristics of Fired Ore}

The typical isothermal reduction curves of fired briquettes reduced under different zone conditions are given in Figure 6. For each single reduction curve, the 


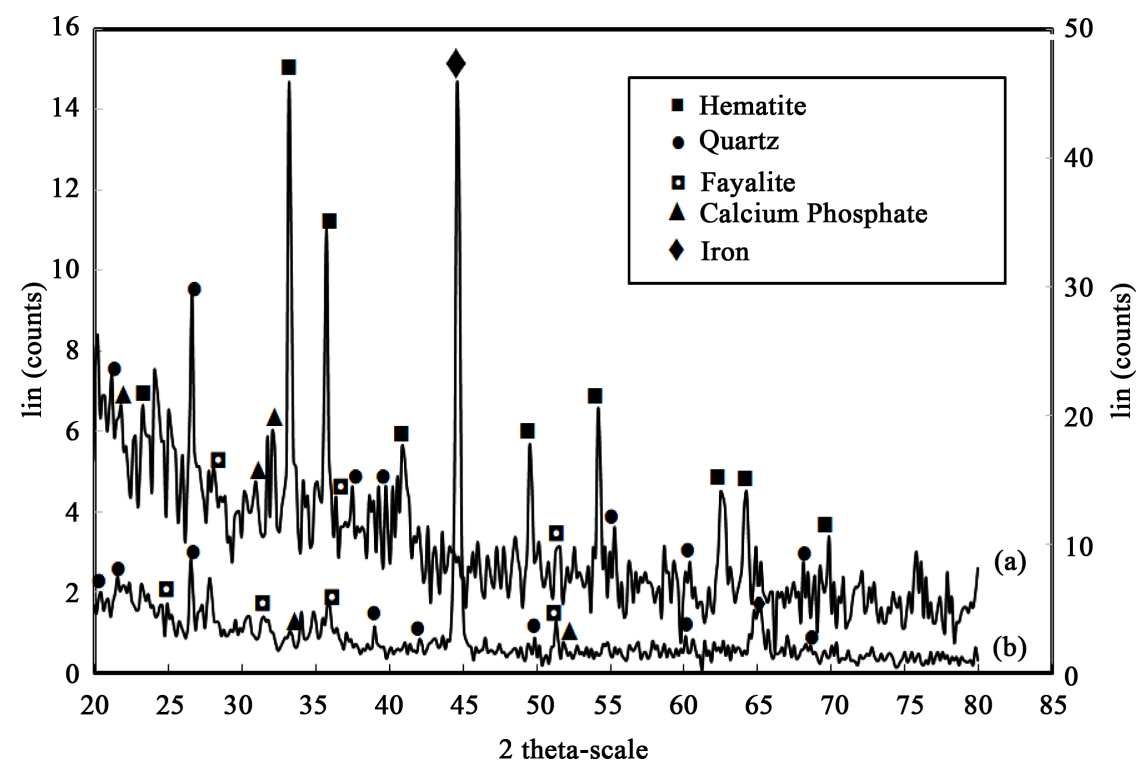

Figure 5. XRD patterns of: (a) Fired sample; (b) Reduced sample.

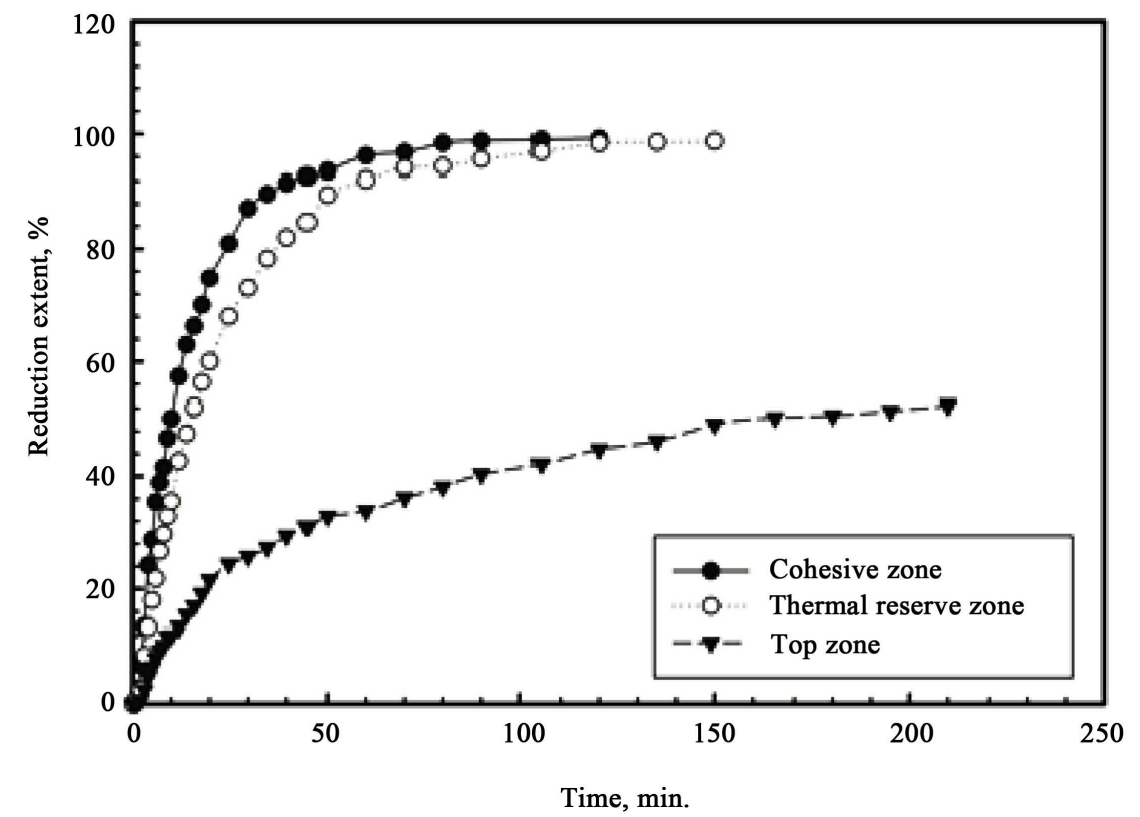

Figure 6. Reduction behavior of fired ore in different zones of blast furnace.

rate of reduction was highest at the early stages and decreased as reduction proceeds till the end of reduction. Two modes of reduction curves can be observed, the first is the reduction curve in the top zone which shows incomplete reduction temperature. By other words, the insufficient ratio of $\mathrm{H}_{2}$ and $\mathrm{CO}$ in the gas mixture together with relatively lower temperature lead to the formation of hardly reducible phases such as magnetite and wustite. The second mode of reduction curves is associated with samples reduced under thermal reserve and cohesive zones. In these zones, the reduction reactions are going to completion and $100 \%$ reduction extents are attained. The reduction rate of samples reduced 
at thermal reserve zone condition is slightly lower than that reduced at cohesive zone condition. The reduction was almost completed after $150 \mathrm{~min}$. but for top zone conditions, the reduction rate is extremely lower than others, the reduction extent reached $50 \%$ after $235 \mathrm{~min}$. After reduction phosphorus is remained in the form of calcium phosphate with metallic iron as main phase beside some quartz and fayalite as shown in Figure 5(b).

All these reduction phenomena are confirmed by the microstructure examination. The microstructures of the unreduced fire samples and reduced samples in the three zones are shown in Figure 7. It was observed that the unreduced grains are most liked separated euhedral crystals accumulated with each other forming clusters with some macro-pores between them Figure 7(a). For the samples reduced by top zone conditions Figure $7(\mathrm{~b})$, agglomeration between grains increased with maintaining the shape of grains but deformation of grains shape occurred and grains started to semi-melted and connected to each other with some macro- and micro-pores distributed inside the structure for samples reduced by thermal reserve zone conditions Figure 7 (c).

\subsection{Comparative Analysis}

A comparative analysis is carried out between green and fired high phosphorus iron ores in reducing atmosphere similar to that in iron blast furnace in order to correlate the effect of different reduction parameters on the reducibility and microstructure changes during reduction processes. The typical reduction curves in Figure 8 show clearly the effect of firing on the reducibility of iron ores. It can be observed that the reduction curves of green and fired samples are almost
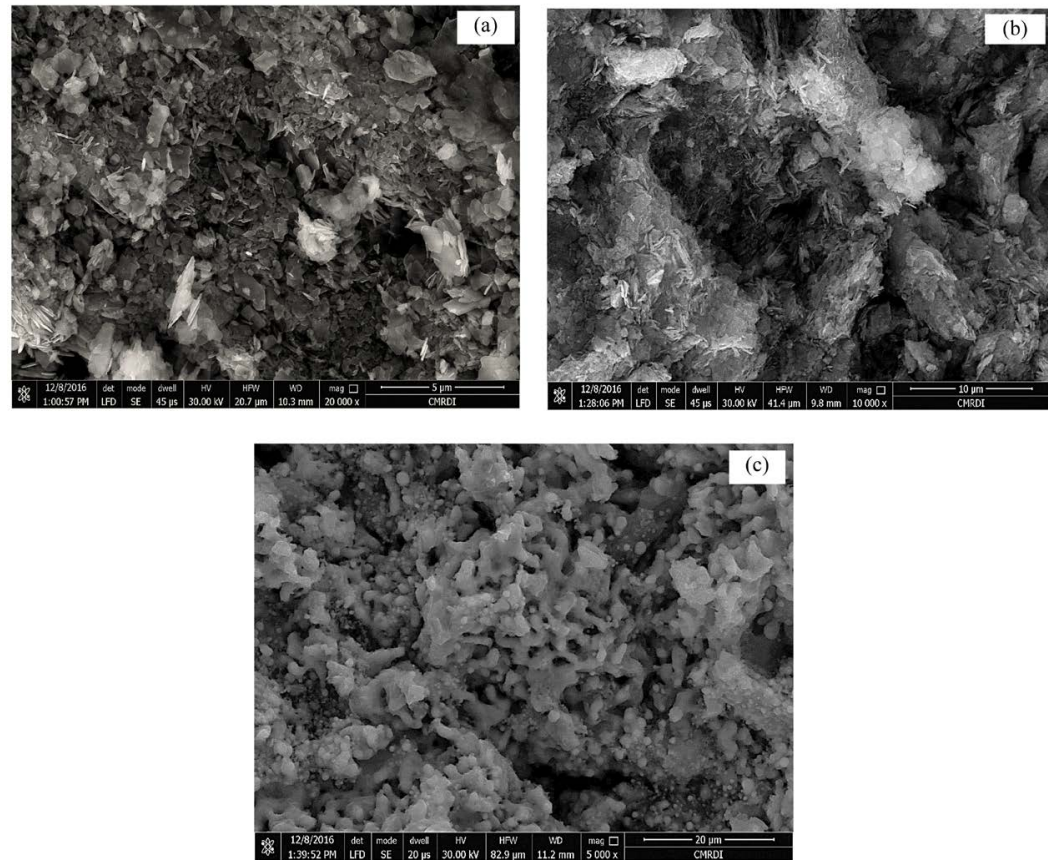

Figure 7. FESEM images for: (a) Fired ore; (b) Reduced at top zone conditions; (c) Reduced at thermal reserve zone conditions. 
congruent at the cohesive zone where all particles become melted due to high reduction power of this zone. On the other hand at the thermal reserve zones and top zone reduction conditions, the reduction rate of fired samples is greater than green samples.

By examination the microstructure of green and fired iron ores reduced by top zone conditions. For green samples, grains are relatively larger and accumulated with each other with few macro-pores in the structure. On the other hand for fired samples, accumulation increased forming clusters and leaving larger macro-pores between them which facilitate access of reducing gas during reduction process. So, the reduction rate of fired samples is greater than unfired ones as shown in Figure 9(a) and Figure 9(b).

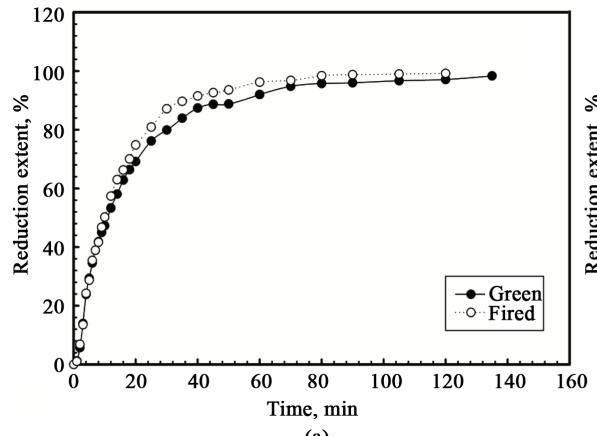

(a)

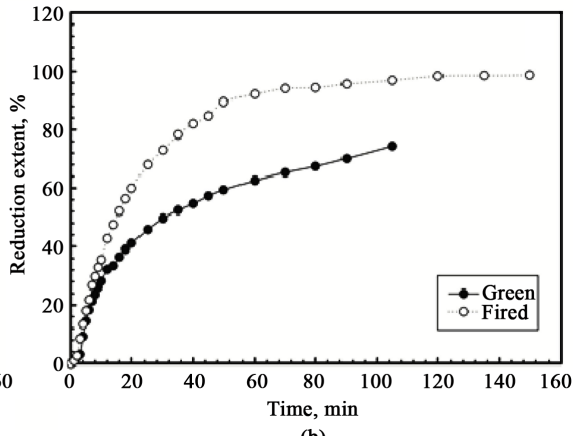

(b)

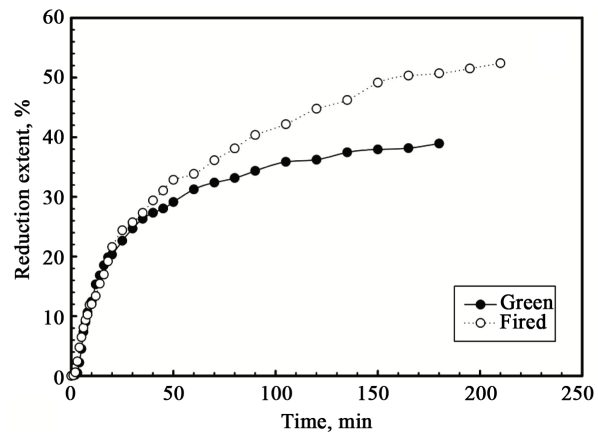

(c)

Figure 8. Reduction behavior of fired samples at different reduction conditions of blast furnace. (a) Cohesive zone; (b) Thermal reserve zone; (c) Top zone.

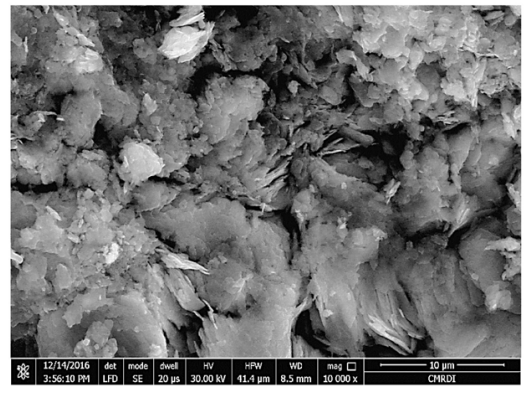

(a)

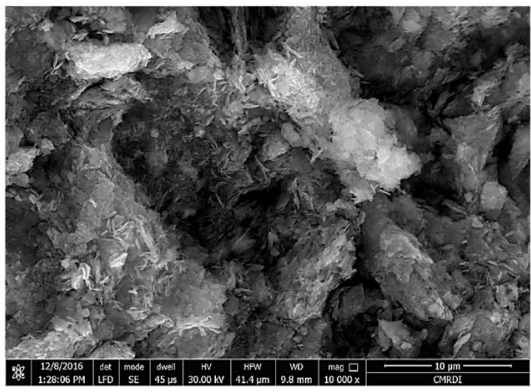

(b)

Figure 9. FESEM images for samples reduced at top zone conditions: (a) Green sample; (b) Fired sample. 


\section{Conclusions}

- High phosphorous iron ore from the Eastern South Aswan region in Egypt was isothermally reduced by different ratios of $\mathrm{H}_{2} / \mathrm{CO} / \mathrm{CO}_{2} / \mathrm{N}_{2}$ which closely represent the temperature and the theoretical composition of gas mixture of different zones of blast furnace.

- Green fired and reduced samples are characterized by X-ray diffraction (XRD), $\mathrm{X}$-ray fluorescence (XRF), optical microscope and field emission scanning electron microscope (FESEM).

- The influence of reduction conditions on reducibility and morphology of reduced samples were investigated.

- Samples were fired at $1000^{\circ} \mathrm{C}$ for 3 hours, then isothermally reduced by the same reduction conditions.

- Fired samples mainly contain hematite phase with crystalline size (41.5 82.6) $\mathrm{nm}$ beside some quartz, fayalite and calcium phosphate.

- The comparative reduction behavior for green and fired briquettes was demonstrated. The reduction curves of green and fired samples reduced at cohesive zone conditions are almost congruent due to high temperature and reduction power at this zone. So, the effect of firing can be hardly distinguished.

- The reduction rate of fired samples is greater than that for green samples which confirmed by morphological examination of the reduced samples. For green samples, grains are relatively larger and accumulated with each other with few macro-pores in the structure. On the other hand for fired samples, accumulation increased forming clusters and leaving larger macro-pores between them which facilitate access of reducing gas during reduction process.

\section{Conflicts of Interest}

The authors declare no conflicts of interest regarding the publication of this paper.

\section{References}

[1] Salem, S.M. and El Gammal, E.A. (2015) Iron Ore Prospection East Aswan, Egypt, Using Remote Sensing Techniques. The Egyptian Journal of Remote Sensing and Space Sciences, 18, 195-206. https://doi.org/10.1016/j.ejrs.2015.04.003

[2] Ivanov, T., Shalaby, I.M. and Abdel Aziz Hussein, A. (1973) Ore Mineralogy of the Serpentinites of Bir. El Kubbania-Um Khros Area, Egypt. Annals of the Geological Survey of Egypt, 3, 75.

[3] Garson, M.S. and Shalaby, I.M. (1976) Precambrian-Lower Paleozoic Plate Tectonics and Metallogenesis in the Red Sea Region. The Geological Association of Canada Special Paper, 14, 573-596.

[4] Sims Paul, K. and James, H.L. (1984) Banded Iron-Formations of Late Proterozoic Age in the Central Eastern Desert, Egypt. Geology and Tectonic Setting Economic Geology, 79, 1777-1784. https://doi.org/10.2113/gsecongeo.79.8.1777

[5] Mucke, A. (2000) Environmental Conditions in the Late Cretaceous African Tethys: 
Conclusions from a Microscopic-Microchemical Study of Ooidal Ironstones from Egypt, Sudan and Nigeria. Journal of African Earth Sciences, 30, 25-46. https://doi.org/10.1016/S0899-5362(00)00006-3

[6] El-Gaby, S., List, F.K. and Tehrani, R. (1988) Geology, Evolution and Metallogenesis of the Pan-African Belt in Egypt. In: El-Gaby, S. and Greiling, R.O., Eds., The Pan-African Belt of Northeast Africa and Adjacent Areas. Tectonic Evolution and Economic Aspects of a Late Proterozoic Orogen, Earth Evolution Sciences, Vieweg, Wiesbaden, 17.

[7] Hussein, A.A.A. and Sharkawi, M.A.E. (1990) Mineral Deposits. In: Said, R., Ed., The Geology of Egypt, Vol. 1, A.A. Balkema Publishers, Rotterdam, 511. https://doi.org/10.1201/9780203736678-26

[8] Edstrom, J. (1986) Optimized Steelmaking from High Phosphorus Ores. Transactions of the Iron and Steel Institute of Japan, 26, 681. https://doi.org/10.2355/isijinternational1966.26.679

[9] Baioumy, H., et al. (2017) Mineralogy, Geochemistry and the Origin of HighPhosphorus Oolitic Iron Ores of Aswan, Egypt. Ore Geology Reviews, 80, 185-199. https://doi.org/10.1016/j.oregeorev.2016.06.030

[10] Matsui, Y., Sawayama, M., Kasai, A., Yamagata, Y. and Noma, F. (2003) Reduction Behavior of Carbon Composite Iron Ore Hot Briquette in Shaft Furnace and Scope on Blast Furnace Performance Reinforcement. ISIJ International, 43, 1904-1912. https://doi.org/10.2355/isijinternational.43.1904

[11] Kumar, M., Jena, S. and Patel, S.K. (2007) Characterization of Properties and Reduction Behavior of Iron Ores for Application in Sponge Iron-Making. Journal of Mineral Processing and Extractive Metallurgy Review, 29, 118-129. https://doi.org/10.1080/08827500701421896

[12] El-Geassy, A.A., Nasr, M.I. and Yousef, M.A. (2000) Behaviour of Manganese Oxides during Magnetising Reduction of Baharia Iron Ore by $\mathrm{CO}-\mathrm{CO}_{2}$ Gas Mixture. Iron-Making and Steel Making, 27, 117-122. https://doi.org/10.1179/030192300677417

[13] Mousa, E.A., Babich, A. and Senk, D. (2013) Reduction Behavior of Iron Ore Pellets with Simulated Coke Oven Gas and Natural Gas. Steel Research International, 84, 1085-1097. https://doi.org/10.1002/srin.201200333

[14] Diemer, P., Lungen, H.B. and Reinke, M. (2011) Utilization of Coke Oven for the Production of DRI. Proc METEC InSteelCon, VDEh, Dusseldorf, 27 June-1 July 2011.

[15] Bahgat, M., Abdel Halim, K.S. and El-kelesh, H.A. (2012) Effect of Nature Gas Injection on Reducibility of Wustite Prepared from Baharia Iron Ore Sinter. Journal of Metallurgical Engineering, 1, 14-22.

[16] Prakash, S. (1996) Reduction and Sintering of Fluxed Iron Ore Pellets-A Comprehensive Review. Journal of the South African Institute of Mining and Metallurgy, 96, 3-16.

[17] Hashem, M.N., Salah, B.A. and El-Hussiny, N.A. (2015) Reduction Kinetics of Egyptian Iron Ore by Non-Coking Coal. Journal of Scientific \& Engineering Research, 6, 846-852.

[18] Babich, A. and Senk, D. (2013) Hydrogen Rich Blast Furnace, Coal Use in Iron and Steel Metallurgy. Woodhead Publishing Ltd., Cambridge.

https://doi.org/10.1533/9781782421177.3.267

[19] Sun, Y.S., Han, Y.X., Gao, P., Wei, X.C., Li, G.F. and Sun, Y. (2015) Thermogravimetric Study of Coal-Based Reduction of Oolitic Iron Ore: Kinetics and Mechan- 
isms. International Journal of Mineral Processing, 143, 87-97.

https://doi.org/10.1016/j.minpro.2015.09.005

[20] Li, J., Wang, P. and Zhou, L. (2007) The Reduction of Wustite with High Oxygen Enrichment and High Injection of Hydrogenous Fuel. ISIJ International, 47, 1097-1101. https://doi.org/10.2355/isijinternational.47.1097

[21] Peacey, J.G. and Davenport, W.G. (1979) The Iron Blast Furnace Theory and Practice. Pergamon of Canada, Ontario.

https://doi.org/10.1016/B978-0-08-023218-8.50005-4

[22] El-Geassy, A.A., Shehat, K.A. and Ezz, S.Y. (1977) Mechanism of Iron Oxide Reduction with Hydrogen/Carbon Monoxide Mixtures. Transactions of the Iron and Steel Institute of Japan, 17, 629-635.

[23] El-Geassy, A.A. (1999) Influence of Doping with $\mathrm{CaO}$ and/or $\mathrm{MgO}$ on Stepwise Reduction of Pure Hematite Compacts. Ironmaking \& Steelmaking, 26, 41-52. https://doi.org/10.1179/irs.1999.26.1.41

[24] El-Geassy, A.A. (1996) Reduction of $\mathrm{CaO}$ and/or $\mathrm{MgO}$-Doped $\mathrm{Fe}_{2} \mathrm{O}_{3}$ Compacts with Carbon Monoxide at 1173-1473 K. ISIJ International, 36, 1344-1353.

https://doi.org/10.2355/isijinternational.36.1344 